\title{
A SWOT Analysis to understand the impact of tourism industry on the Three pillars social Economy and Environment
}

\author{
Mejjad Nezha ${ }^{1,2}$, Alessia Rossi ${ }^{3}$, Khalid El Khalidi², Ana-Bianca Pavel ${ }^{4}$, El Khalil Cherif ${ }^{5}$, Otman El Ouaty ${ }^{6}$, Ahmed \\ Fekri $^{1}$ \\ ${ }^{1}$ Department of Geology, LGAGE, Faculty of Sciences Ben M'Sik, Hassan II University, B.P 7955, Casablanca 20670, Morocco. \\ ${ }^{2}$ Department of Geology Laboratory of GMSSURAC 45, Faculty of Sciences, Chouaib Doukkali University, El Jadida 24000, \\ Morocco. \\ ${ }^{3}$ Convention \& Visitors Bureau Chianciano Terme, Via Sabatini, 7 - 53042 Chianciano Terme (SI), Italy. \\ ${ }^{4}$ National Research and Development Institute for Marine Geology and Geoecology - NIRD GeoEcoMar, Constanta Branch 304 \\ Mamaia Blv., RO-90058. Constanta, Romania. \\ ${ }^{5}$ Institute for Systems and Robotics, Instituto Superior Técnico, University of Lisbon, 1649-004 Lisbon, Portugal. \\ ${ }^{6}$ Department of Geology, Faculty of Sciences, Abdelmalek Essaadi University, 93000 - Tetouan, Morocco.
}

\begin{abstract}
The tourism industry is an important sector contributing to the world economy where many countries' economies worldwide depend mostly on the tourism industry incomes. In the present study, we analyze and review the tourism industry strength, weaknesses and opportunities in Morocco through applying Strength, Weakness, Opportunity, and Threat (SWOT) analysis. The study highlights the importance of the tourism sector for the socio-economic growth and development of the Moroccan economy and the need to preserve the country's natural and cultural wealth by adopting environmentally sustainable practices.
\end{abstract}

\section{Introduction}

The tourism industry has significantly developed in the latest decades, and its contribution to the countries economy has largely enhanced especially coastal tourism. The growth of this industry is mainly related to the availability, prices and development of technology associated with aerial transport. This tourism-related development has positively affected countries' social and economic growth, but recently, many studies showed that tourism industry-related activities negatively impact the ecological, cultural, and environmental quality of touristic areas [1-4].

In Morocco, the tourism industry has become an omnipresent component allowing economic and social growth as the Moroccan country has great touristic potential. 13 million tourists have visited Morocco during 2019, which ranked it as the $1^{\text {st }}$ most visit country in Africa in $35^{\text {th }}$ at the international level [5].

The privileged geographical location of the Moroccan Kingdom makes it an ideal area to offer sun and beach tourism, especially with its extensive coastline distributed between the Mediterranean and the Atlantic. Besides the different climates that characterize Morocco from the North, which is known for its various blue Azur beaches to the South, where nature is wilder and beaches with the vast sand dunes of Moroccan Sahara.

This sector is in continuous development and generates many goods at different levels, economic and social, through creating jobs. The tourism industry in Morocco can be divided into three categories: i) historical and cultural tourism where people visit old
Moroccan imperial cities such as Fez, Meknes, and Marrakesh; ii) Sun and beach tourism, where most visitors come to coastal cities during the summer season and iii) recreation and nature-based tourism where people are interested in landscape (e.g. deserts and mountains ..) [6].

Tourism activities are indeed vital for the economy of the whole country, but unsustainable tourism-related practices affect the environment negatively and lead to the degradation of cultural and ecological sites [7-11]. Accordingly, in the present work, we seek to

- Analyze and review the Moroccan strategy for developing the tourism sector;

- Identify the main strength, weaknesses and threats related to tourism industry growth in Morocco,

- Define what opportunities could this sector provide at all levels.

- Determine the possible effects of the continuous growth of this sector on the environment and on the tourism sector itself.

\section{Methods}

\subsection{Study Area}

Morocco is located in North Africa more precisely. The Moroccan Kingdom is the northwestern-most country in the region of the Maghreb, which is situated in North Africa. It is limited in the North by the Mediterranean sea and in the west by the Atlantic Ocean. Morocco has land boundaries with algeria to the east and Mauritania to the South. 
The privileged geographical location of Morocco near to the mouth of the Mediterranean and as the main door to Europe attract tourists from many countries, especially with the unique and particular ecological, cultural and historical heritage that characterize this country. Besides, the beautiful Moroccan beaches are attracting visitors from different countries (Figure 1).

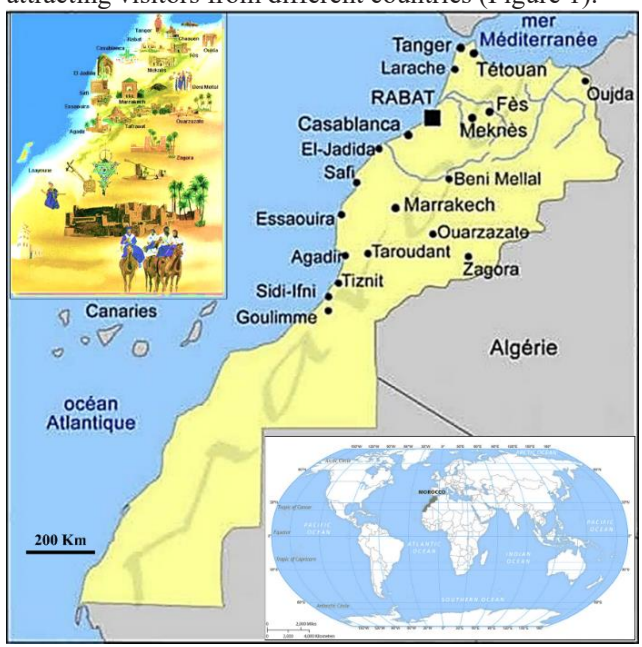

Fig .1. Moroccan map and main touristic cities.

\subsection{SWOT Analysis}

SWOT analysis was first used in the 1970s as a tool for business management (Porter, Harvard University). This analytical approach assesses the Strengths (S), Weaknesses (W), Opportunities (O), and Threats (T) of an organization, industry, company, sector [12] or ecosystem. It is used to evaluate internal (Strengths and Weaknesses) and external (Opportunities and Threats) factors allowing better guidance and identification of the current and future potential.

The SWOT analysis is a widely used tool for organizing information with respect to situation analysis. When presented as a SWOT matrix, strategic planning can be used, including environmental planning and management (e.g. [13-14]).

In the tourism sector, several authors have used the SWOT analysis to understand better the challenges the tourism sector faces at different levels, including the environmental side [15-19].
Helpful to achieving the Sustainability.

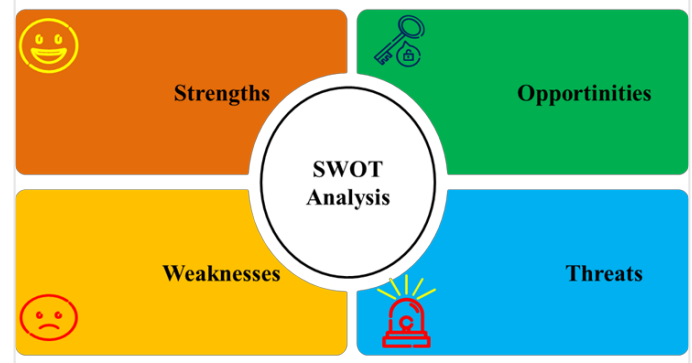

Harmful to achieving the Sustainability.

Fig .2. SWOT model.

\section{Results and Discussions}

\subsection{Literature review}

\subsubsection{Moroccan strategy for developing the tourism sector}

The tourism sector has a crucial role in the Moroccan economy as it represents $7 \%$ of the country GDP (gross domestic product) [20]. The Moroccan Tourism Observatory explained that due to the geographical location, Morocco's natural resources, cultural and historical heritage placed it as a country with a pure tourist vocation (around 13 million non-resident tourists recorded in 2019) [21]. Accordingly, Morocco is currently positioned as Africa's most visited and popular destination.

Likewise, all countries with cultural and historical heritage, natural and ecological wealth, Morocco sees the tourism sector as a potential driver leading to social and economic growth. It should be noted that tourism is among the rapidly growing economic sectors [22-23], especially it compromises a set of interlinked sectors of activity such as car rental, accommodation for visitors, travel agencies, food, shopping, cultural activities and other recreational activities. In this order, Under the high patronage of HM the King, the Moroccan government conduct a prospective study on the Moroccan tourism sector by 2030 based on the 2010 and 2020 vision achievements [6, 24-25].

Vision 2010 was mainly dedicated to improving the tourism sector overall indicators, while vision 2020 (Called Plan Azur) focused on sustainability and ecotourism and sought to enlarge the Moroccan appeals to comprise its rich diversity of the countryside for example, deserts and mountains. This strategy main goals are as follow: i) Making Morocco among the world's top twenty destinations; ii) Increasing and doubling the industry size through creating around 470,000 new jobs, through which the share of tourism in GDP will grow by $2 \%$, and the tourist's number will be more than double to reach in 2020, 140 billion MAD; iii) implementing a policy for improving Morocco's 
good and services offering to tourists; iv) ensuring sustainable development of the sector and delivering novel institutional arrangement [26]. In addition, the creation of eight destinations (Tourism territories) for touristic purposes from the North to the South of the Moroccan Kingdom is one of the crucial pillars of the 2020 vision (Figure 3).

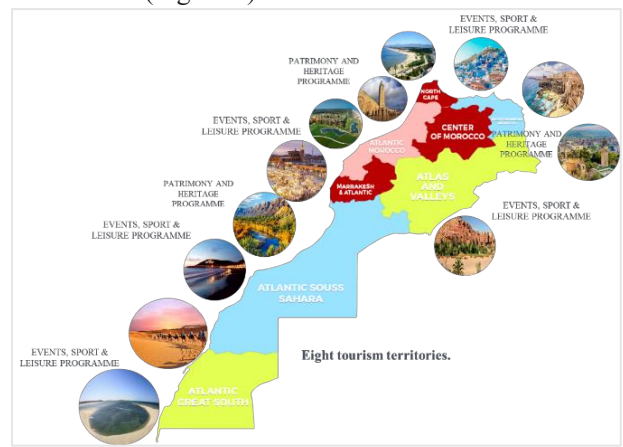

Fig.3. The eight structured destinations (Tourism territories) for touristic purposes.

Besides, six framework programmes were structured in order to provide a varied product range) [25] :

i) The AZUR 2020 Programme sought to reinforce the entertainment and leisure offer and integrate the diverse ecological aspects by building competitive Moroccan seaside offer at the international level.

ii) Patrimony and heritage programme: aims to improve the Moroccan cultural identity through highlighting both intangible and tangible patrimony and heritage.

iii) Events, sport and leisure programme: related to creating varied and rich entertainment services and offer for tourist satisfaction.

iv) The Eco \& sustainable development program aims to develop the "carbon neutral" and production of clean energy, reducing $\mathrm{CO} 2$ emission generated by economic and tourist activities.

v) High-value Addedniche programme (business and well-being)

vi) Biladi programme (The Internal Tourism Program): sought to satisfy the national tourist's needs and meet their expectations by strengthening and completing the already lunched projects over the past decades.

Thus, the Moroccan approach established aims to develop a model of tourism sustainability in the
Mediterranean area by providing new and diversified tourist products.

\subsection{SWOT ANALYSIS}

\subsubsection{Strengths}

Morocco is located in the North of Africa and is considered the door to Africa and Europe. By its diversified culture, history, climate, Morocco has many advantages and strengths (Figure 4) that enable it to compete very well in the African and international tourism industry.

Morocco's political stability and geographical location near to Europe are among the factors that encourage tourists to visit Morocco, especially from France, Italy, Spain, UK and U.S. [27]. Besides, the pleasant climate and highly diverse landscape that distinguish this North African country from other countries attract tourists from worldwide. The Atlas Mountains, the vast stretches of Mediterranean and Atlantic coastlines, the Sahara desert, the forests in the rif, the fauna and flora diversity positioned Morocco as African first tourist power.

The rich and fascinating Moroccan kingdom historical heritage with imperial cities intriguing with footprints of ancient generation and their cultures attract people worldwide to visit and discover other countries culture and history. Fez, Marrakech, Mèknes and Rabat, the four Imperial cities in the Moroccan kingdom's known as the four historical capital, offer exciting and charming historical places. Besides, Fez is the scientific capital of Morocco and houses the world's oldest continuously functioning university and is also registered as a World Heritage Site by UNESCO [28].

In addition to the historical attractions that include Roman monuments, old medina's, coastlines, beaches, Morocco is known for its unique and rich traditional culture such as music, art, and gastronomic tradition. In fact, the diversity of Morrocan gastronomy plays a crucial role in supporting the destination attractiveness confirmed in the study carried out by El Hafid et al, 2018 [29], where local gastronomy is defined as an essential attribute in health, business and religious tourism. In contrast, local gastronomy was considered a complementary element for cultural and recreational tourism [29].

Morocco has many tourist strengths that could enable it to be among the world's top 20 destinations if it takes advantages and profits from these strengths adequately. 


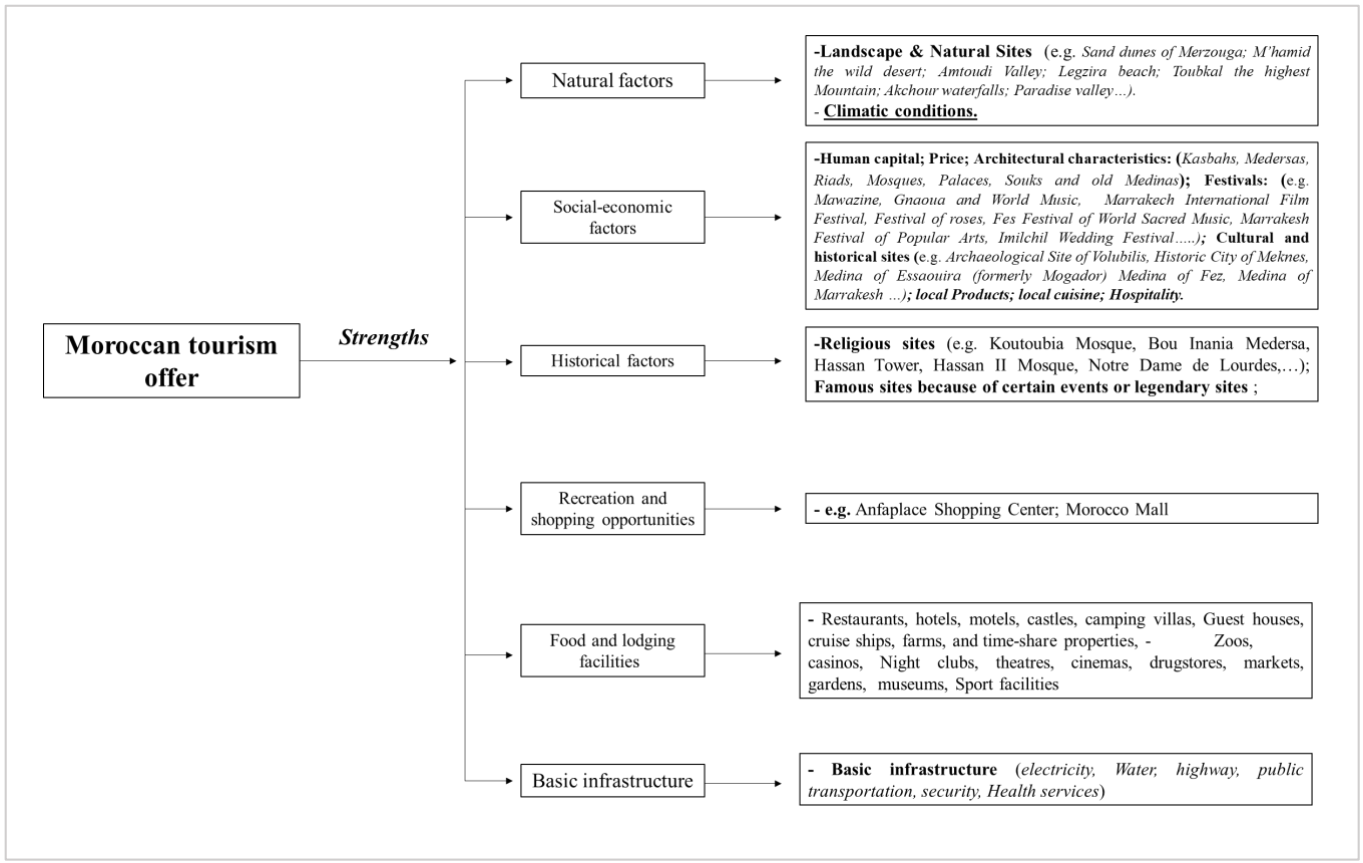

Fig .4. Main strengths that Moroccan tourism offer.

\subsubsection{Opportunities:}

As we defined the main strengths that the Moroccan tourists offer, many opportunities to mention including:

$>$ Environmental and civic awareness (about the importance of the tourism sector for the social and economic sector);

$>$ Reinforce and strengthen the nature-based and cultural heritage ;

$>$ Develop the concept of the "Blue tourism";

$>$ Adopting green building while executing touristic related infrastructure and building (eco-friendly material construction and Renewable energy).

$>$ Enhance the education and social media trends to make the travel culture more prevalent for the younger generations and branding the Moroccan tourist offer

$>$ Authenticity / experiential \& more environmentally conscious tourism;

$>$ Gastronomic tourism (ex: oyster and mussels... seafood, ..)

$>$ Stakeholders' openness to innovation (e.g. use of clean energy in the hotels for production of energy);

$>$ Reinforce the human capital, and increase the interest of local citizens in domestic tourism;

$>$ Implementing a new policy to protect the environment and structuring a strategy that sought to expand the green zone in the whole country;

$>$ Promoting recreational tourism among local citizens;
Develop innovative marketing strategies in order to sell tourist-related products for

$>$ Foreigners and local citizens;

$>$ Creating jobs and generating benefits for the local community by increasing community-level entrepreneurship.

\subsubsection{Weakness:}

The main weaknesses can be mainly related to:

$>$ High population density on littoral areas during the summer;

$>$ Low environmental education of most population;

$>$ Seasonality of the tourism, especially for coastal cities;

$>$ A weak usage of the country's natural resources and natural beauty;

$>$ A gap of knowledge regarding the recreational and cultural tourism among national citizens;

$>$ Lack of knowledge on evolving sustainable tourism products;

$>$ Tourism supply chain and marketing is not well developed;

$>$ Lack of community representation in tourism decision making;

$>$ Lack of academic research related to tourism;

$>$ Less use of tourism potentials of Moroccan touristic sites to attract tourists. 


\subsubsection{Threats:}

It can be divided into direct and indirect threats.

Direct threats, especially to the environment and natural resources, which are mainly related to :

$>$ Degradations and alteration of natural landscapes and land use and occupation changes due to the building of hotels and mega tourism construction;

$>$ Threat to the local tradition and culture from tourists;

$>$ Overpopulation and overconsumption of natural resources;

$>$ Climate change;

$>$ Environmental pollution \& degradation;

$>$ Air pollution, increase of lettering and solid waste amount especially in coastal areas and forests;

$>$ Overconcentration of tourism activities in coastal areas leading to degradation of these ecosystems;

$>$ Biodiversity disturbance and habitats loss. The transformation of land to tourist buildings leads to biodiversity loss through dividing animal populations and limiting their free movement [30].

$>$ Rise of the prices of goods and services including transportation fees, accommodation;

$>$ Natural resource depletion due to overexploitation to meets the increasing demand and satisfies the tourist needs and wants.

The impact of the impact can translate into indirect threats. The increase of tourism-related activities positively impacts the economy and social sectors by creating job opportunities and increasing local community livelihoods. Nevertheless, when this increase is not well balanced with the environment component, it puts at risk the tourism industry sustainability. The tourism sector is mainly based on nature and landscape beauty and natural resources availability. Thus the overexploitation and overconsumption of natural resources during the high season leads to depletion of these resources (e.g. Fisheries) and then threatened the destination attractiveness and consequently the tourism sector.

\section{Conclusion}

In Morocco, tourism plays a crucial role in the country's economy and contribute significantly to job creation. Conversely, tourism was also identified as environmentally destructive of land because it has impacts on the landscape and coastal areas.

The use of SWOT analysis in the present study indicated common strengths, opportunities, weaknesses and threats that can be highlighted for ensuring sustainable growth of this industry. It can be concluded that the tourism industry growth depends mainly on the environmental quality of the tourist destination and natural resources availability; thus, adopting environmentally sustainable practices can convert the weakness to strengths and opportunities while reducing and avoiding threats.
Finally, tourism is an essential driver of economic growth of many regions around the Moroccan Kingdom and could be seen as a priority sector for sustainable economic development and growth in the whole country. Thus, to promote and sustain the development of this industry, all administrative, scientist and professional actors need to be aware of the necessity of creating new strategies for tourism development, which should be concerted, credible and long-term established.

\section{References}

1. U. Sunlu. In : Camarda D. (ed.), Grassini L. (ed.). Local resources and global trades: Environments and agriculture in the Mediterranean region. Bari: CIHEAM, (2003).

2. V. Asero, S. Skonieczny. Tourism and Travel Behavior - Contexts and Boundaries, Leszek Butowski, (IntechOpen 2017).

3. S. Stavros, S. Fani, T. Stergios, S. Ioannis, Ch. Olga. Int. Quart. Sci. J. 15, 3 (2016).

4. M. Grelaud, P. Ziveri. Sci Rep 10, 20326 (2020).

5. World data, Tourism in Morocco. Available athttps:/www.worlddata.info/africa/morocco/touri sm.php (2020) (Accessed 02 June 2021).

6. J. Steenbruggen. Tourism Hospit 5: 224 (2016).

7. E.K. Cherif, M. Vodopivec, N. Mejjad, J.C.G.E. Da Silva, S. Simonovi c, H. Boulaassal. Water 12 , 2638 (2020).

8. N. Mejjad, A. Laissaoui, A. Fekri, N.E.H. Hassen, A. Benmhammed, O. El-Hammoumi, A. Benkdad, H. Amsil. Inter. J. Envir. Analy. Chemi. (2020).

9. N. Mejjad, A. Laissaoui A. Fekri, A. Benmhammed, O. El Hammoumi, E. K. Cherif. In Proceedings of ACM GEOIT4W-2020, March 11-12, 2020, Al-Hoceima, Morocco.

10. E. K. Cherif, F. Salmoun, F. Javier MesasCarrascosa. Remote sens. 11, 972 (2019).

11. N. Mejjad, A. Laissaoui, O. El-Hammoumi, A. Fekri, H. Amsil, A. El-Yahyaoui, A. Benkdad. Environ. Sci. Pollut. Res. 25, 22872-22888 (2018).

12. G-Y. Gao, D-H. Peng. Knowl. Based Syst. 24 (6), 796-808 (2011).

13. E. K. Zavadskas, Z. Turskis, J. Tamosaitiene. Archives of Civil and Mechanical Engineering, Vol. XI, 4, 1063-1082 (2011).

14. R. Scolozzi, U. Schirpke, E. Morri, D. D’Amato, R. Santolini. JEM. 146, 543-551 (2014).

15. B. Goranczewski, D. Puciato 2010. Tourism (2010).

16. S.H. Mojaveri, H. Fazlollahtabar. Review of International Comparative Management. 13, 1, (2012)

17. Md. Sanaul Haque Mondal. UTMS Journal of Economics 8 (2) (2017).

18. N. Kişi. Sustainability 11, 964 (2019).

19. S. Özüpekçe. IJHSSI 8, 05 (2019). 
20. WTO. International Tourism Highlights, 2019 Edition, UNWTO, Madrid, Spain (2019).

21. A. Elouali, S.Hafidi Alaoui, N. Ettahir, A. Khohmimidi, N. Motii, K. Rahali, M. Kouzer. Adv. in Sci. Tech. \& Eng. Sys. J. 5, 6, (2020).

22. N. Vanhove. Elsevier Inc.2. (2005).

23. N. Salish, P. Rodrigues. Tourism Economics (pp. 183-210). Springer-Verlag Berlin Heidelberg (2011).

24. Hcp. Prospective Maroc 2030: Tourisme 2030, quelles ambitions pour le Maroc? Available at https://www.hcp.ma/downloads/Maroc-

2030_t11885.html. (Accessed June 30 2021) (2011).

25. C. El Aouami, A. Louhmad. 2020. EJBMR, Research 5, 5, (2020).

26. N. Roudies. Expert Group Meeting on Ecotourism, Poverty Reduction \& Environmental Protection Moroccan Ministry of Tourism (2013).

27. Morocco World News. Nearly 13 Million Tourists Visited Morocco in 2019. Available at

https://www.moroccoworldnews.com/2020/02/292 688/nearly-13-million-tourists-visited-morocco-in2019. (Retrieved on 25 June 2021).

28. UNESCO. https://whc.unesco.org/en/list/170

29. M.El Hafid, H. El Assri, A. Sair In: V. Katsoni, K. Velander (eds) Innovative Approaches to Tourism and Leisure. Springer Proceedings in Business and Economics. Springer, Cham. (2018)

30. UNWTO. Tourism and Biodiversity - Achieving Common Goals Towards Sustainability. World Tourism Organization: Madrid, Spain, (2010). 